\title{
Zircon as an oxybarometer
}

\author{
A.J. BERRY* AND L.J. CRISP
}

Research School of Earth Sciences, Australian National

University, Canberra, ACT 2601, Australia

(*correspondence: Andrew.Berry@anu.edu.au)

The redox variability of $\mathrm{Ce}(3+, 4+)$ and $\mathrm{Eu}(2+, 3+)$ results in the preferential uptake of $\mathrm{Ce}^{4+}$ and exclusion of $\mathrm{Eu}^{2+}$, relative to the other exclusively trivalent rare earth elements (REE), by zircon crystallising from a melt. This results in $\mathrm{Ce}$ and $\mathrm{Eu}$ "anomalies". The magnitudes of these anomalies will depend on the amounts of $\mathrm{Ce}^{4+}$ and $\mathrm{Eu}^{3+}$ in the melt. The amount of an oxidation state is controlled by both the overall abundance of the element (e.g. depletion of Eu by prior crystallisation of plagioclase) and the $\mathrm{Ce}^{4+} / \mathrm{Ce}^{3+}$ and $\mathrm{Eu}^{3+} / \mathrm{Eu}^{2+}$ ratios, which reflect the oxygen fugacity $\left(f \mathrm{O}_{2}\right)$.

$\mathrm{Ce}^{4+} / \mathrm{Ce}^{3+}$ and $\mathrm{Eu}^{3+} / \mathrm{Eu}^{2+}$ will vary at constant $\mathrm{fO}_{2}$ due to differences in melt composition, temperature, and pressure. Partitioning experiments as a function of these variables should allow the magnitude of the anomalies to be calibrated for $f \mathrm{O}_{2}$. However, it is experimentally difficult to produce crystals of zircon of sufficient size for analysis by LAICPMS, which has appropriate detection limits and allows the full REE pattern to be determined.

We have undertaken over 350 zircon-melt REE partitioning experiments using nine synthetic compositions ranging from andesitic to granitic (ASI of 0.2-1.15), at temperatures from $800-1400{ }^{\circ} \mathrm{C}$, pressures from $0.001-4 \mathrm{GPa}$, and $f \mathrm{O}_{2} \mathrm{~s}$ from QFM-3 to QFM+12 (where QFM is the $f \mathrm{O}_{2}$ in $\log$ units relative to the quartz-fayalite-magnetite buffer). The concentrations of REE in zircon crystals less than the size of the LA-ICPMS analysis spot were determined using a two component regression method. The resulting data set was fit to a multi-component model to produce an expression that relates the magnitude of the $\mathrm{Ce}$ anomaly to all the experimental variables. Thus, if the composition of the host rock and zircon crystallisation temperature are known, then $f \mathrm{O}_{2}$ can be determined from the zircon REE pattern. Our expression allows $\mathrm{fO}_{2}$ to be predicted within $2 \log$ units. This is a new geochemical tool for estimating the $\mathrm{fO}_{2}$ of intermediate to felsic melts.

We also determined the partitioning of REE between melt and different sectors of sector zoned zircon. The partition coefficients of $\mathrm{Ce}^{4+}$ are independent of sector, whereas those for $\mathrm{REE}^{3+}$ vary by over an order of magnitude. This results in differences in the $\mathrm{Ce}$ anomaly and hence estimated $f_{2} \mathrm{~s}$, which can vary by up to $4 \log$ units between sectors. The major limitation of zircon as an oxybarometer is zoning in REE concentrations, the effect of which may be reduced by whole crystal analyses. 